\title{
AN EVALUATION OF THE CONSERVATION AREAS AND THEIR IMPORTANCE TO THE ECONOMY OF SOUTH WEST AFRICA
}

\author{
B J G DE LA BAT
}

Division of Nature Conservation and Tourism

Administration of South West Africa

Private Bag X13267

Windhoek

9000

\section{Introduction}

During 1975 the tourist industry was worth between R35-R40 million to the economy of South West Africa (SWA). The figures are based on a survey conducted by the Bureau of Economic Research of the University of Stellenbosch. By far the most important tourist attractions of the Territory lies in its various conservation areas whether they are thermal springs, wilderness areas, national parks, game and nature reserves, hunting farms, coastal recreation areas bird sanctuaries, or natural monuments. The different categories of conservation areas are planned on a national scale according to the capabilities of the various land classes, available resources and the needs and requirements of the local population and tourists from different countries.

For a meaningful evaluation of our conservation areas and their importance to our economy, it is necessary to look briefly at the Territory as a whole because geographic and demographic features, natural resources and climate in particular, to a large extent dictate what can be undertaken in the field of conservation and tourism in each case.

In our land-use planning we are endeavouring to utilize the negative features of the country to our advantage. Judging from experience, we are on the right track although this does not mean that no problems exist.

The land, the people and their problems

The SWA Survey (1974) paints a harsh picture of South West Africa. It is a vast, sparsely-populated, desert-like territory sprawled along the Atlantic seaboard in the south-western portion of Africa. The total area of the country is $824269 \mathrm{~km}^{2}$ which is two-thirds the size of the Republic 
of South Africa or four times the size of the United Kingdom. The population is, however, only 852000 . The reason for this is that, through the lack of water, SWA is a hard, forbidding land. Save on the northern and southern borders, the Territory lacks perennial rivers and its rainfall is low and variable, so that over virtually the whole of it, desert or semi-desert conditions prevail which are periodically aggravated by prolonged droughts.

The Namib Desert constitutes about a fifth of the area of South West Africa. This desolate strip of sand desert between $80 \mathrm{~km}$ and $120 \mathrm{~km}$ in width, with the highest sand dunes in the world, extends along the entire coast line. The cold Atlantic with its strong Benguella current and frequent fogs, makes the Skeleton Coast dangerous to shipping as is evidenced by numerous wrecks. The Central Plateau, which lies east of the Namib, offers a diversified landscape of rugged mountains, rocky outcrops, sandfilled valleys and plains.

Dense vegetation is confined to the north and northeast of the Territory. The areas to the west of the escarpment are so barren as to preclude any form of agricultural exploitation. In the central region the vegetation changes gradually from an arid shrub variety to open thorn savannah and scattered trees towards the north.

Agricultural and industrial development is seriously hampered by a lack of water. Normal dry-land cropping can be practised over only $1,1 \%$ of the Territory's surface while a diversified stock farming industry utilizes the major portion of the remaining land surface. The carrying capacity of the natural pasture could generally be regarded as low.

The Territory has one of the lowest population density figures in the world. The population is made up of Afrikaans, English and German speaking whites, Wambos, Hereros, Namas, Damaras, Rehoboth Basters, Bushmen, Tswanas and Coloureds.

Diamonds and a few minerals provide the bulk of the mineral production and contribute about one quarter of the Gross Domestic Product. This however, is a non-renewable resource and will be exhausted in the foreseeable future. Commercial fishing has become one of SWA's principal industries but it is threatened by over-fishing by foreign vessels outside the territorial waters. Basic features of the agricultural economy are its vulnerability to climatic factors and stock disease, its dependence on cattle and Karakul sheep and the long distances from markets.

Despite these growth-restraining factors, the Territory's 1973 Gross Domestic Product of R615 million was more than four times as high as in 1960. Indicative of progress as these figures are, SWA's economy is still in its infancy. Half the economic output is accounted for by primary industries - agriculture, fishing and mining - which are highly vulnerable to fluctuations in demand and to climatic and other natural factors. South West Africa is therefore clearly a developing country beset by many problems. 


\section{Conservation and tourism assets}

What was said so far sounds like a bleak and dismal picture. But look at it from a conservation and tourism point of view.

With the world population exploding exponentially, elbow room is becoming one of the scarcest commodities today. We had ample land and could proclaim our parks and reserves from north to south and from east to west. In doing so we have spread the benefits of tourism over the whole of the country. In addition most towns are relatively near a park or a resort which fulfils its outdoor recreation needs. This system is also advantageous to the visitor who can now undertake circular tours and see a variety of attractions without overcrowding.

We were also able to create vast parks and reserves in areas not suitable for farming but ideal for tourism. The sheer size of these conservation areas ensures our ability to cope with future demands. I am referring to areas such as the Etosha National Park (2 227000 ha), known for its big game and large herds of plains animals, the Namib Desert Park (1 409500 ha) with the living fossil plant Welwitschia mirabilis and its splended desert scenery, the Fish River Canyon Park (96 $117 \mathrm{ha}$ ) which is comparable to the Grand Canyon of America and which is a popular wilderness area and the Skeleton Coast Park (1 $639000 \mathrm{ha}$ ). In future these parks should increase in importance to the economy of the country.

When it comes to the administration of our natural assets, our small population also proved to be a blessing in disguise. We could not afford a large burocratic machine and different boards to deal with national parks, nature conservation, tourism, public resorts and outdoor recreation. All these functions were concentrated into one department with two advisory boards. Not only does this effect a considerable saving in manpower and funds and speed up decision making, but it eliminates endless committee meetings, reports, empire building and clashes of interest. It is to the advantage of the tourism as well as the administration, to have one centralised authority to deal with all tourist amenities such as parks, resorts, mineral springs, hotels, restaurants, caravan parks, safari-undertakings, guest farms and hunting farms. Standards can be laid down and maintained. The tourist gets value for his money but, more important, this ensures that the infrastructure of the country does not get overloaded by mass tourism and that natural attractions are not overexploited or degraded. Whether such a system would be feasible for a large country, is debatable. We only have a total of 2500 hotel beds in SWA and another 2500 beds and 1500 overnight camping sites in our conservation areas. Our system meets our requirements.

South West Africa is not a pretty country but neither is it a monotonous country. It is a land of vivid contrasts which makes it interesting. Geologically speaking the Namib is the oldest desert in the world with the highest sand dunes $( \pm 500 \mathrm{~m})$ facinating many visitors. 
Our coast line of $1623 \mathrm{~km}$ long, can be divided into three parts. The southern part is a diamond area in which visitors are not allowed except at the harbour town of Luderitz where an area of approximately $100 \mathrm{~km}^{2}$ is being developed as the Diamond Coast Recreation Area. The middle part of the coast has been proclaimed the National West Coast Recreation Area ( $\pm 750000 \mathrm{ha})$ and the northern part the Skeleton Coast Park (1 639000 ha).

No private development is allowed on the coast outside coastal towns. To combat pollution and to preserve the fragile ecology of the desert coast, visitors are compelled by law to overnight either in official caravan parks, rest camps and camp sites or in accommodation establishments in the towns.

The Atlantic Ocean is cold and dangerous for swimming. The beaches are devoid of waving palms and in winter it becomes quite cold. On the other hand the sea is practically a "plankton soup" or a "sardine pie" which makes it an angler's paradise. This is also the reason for the presence of literally millions of seabirds of a great variety and many fur seals which are an attraction on their own. The rainfall is very low. A cool fog envelopes the coast when the sun becomes too hot. No wonder our West Coast attracted some 80000 visitors last year and the main centre, Swakopmund, is experiencing a boom period.

According to Giess (1971) there are 15 major veld types in SWA ranging from winter rainfall desert and succulent Karoo to the northernly Kalahari tree and savannah woodland which extend from true desert to fully aquatic habitants with animals such as lechwe and hippo. We have established a park or reserve in 13 of the 15 biotic communities and not two of our reserves are exactly alike. Furthermore, the Historical Monuments Commission proclaimed a large number of natural phenomena, such as the Hoba Meteorite (the biggest in the world), "bottomless" lakes, mountains and canyons as natural monuments. Safari-undertakings thrive by taking visitors to these areas.

Together with a superb summer climate on the coast with a low rainfall, we also enjoy mild winters without rains or storms when much of southern African shivers. South West Africa also has a surplus of sunshine which aid our attempts to attract overseas visitors. Windhoek, for instance, has an average of 318 days of sunshine per annum. Therefore we do not need expensive indoor recreation facilities to attract visitors.

Due to the scarcity of water, the government had to embark on the construction of large state water schemes such as the Hardap and Von Bach dams. These dams were developed into recreation resorts which fit into our chain of rest camps. They also serve to accommodate visitors who would otherwise overcrowd our more sensitive parks and reserves.

Because it could easily become uneconomic to farm where the average rainfall is less than $100 \mathrm{~mm}$ per annum or where underground water is scarce, the Administration of SWA bought up a number of unprofitable 
farms and added them to existing conservation areas. The Waterberg Plateau Park (40000 ha) with its massive sandstone cliffs and the Naukluft Mountain Zebra Park (91 000 ha) are good examples. Animals such as gemsbok, eland, springbok, mountain zebra, ostrich and others are adapted to arid conditions and thrive where domestic stock struggle. As a result of this, unproductive land can be made economically viable. Tropical diseases, tsetse flies and bilharzia do not occur in arid areas. This is a boon to tourism.

The low percentage $(1,1 \%)$ of SWA which could be regarded as arable, probably saveguarded the survival of our wild-life. By nature cattle and karakul farming leaves room for wild animals as the original vegetation remains available. Predators had to be controlled. According to our latest statistics some 700000 game animals occur on farming land alone. In 1967 the Nature Conservation Ordinance was amended whereby game became the property of the farm owner. Against general expectations farmers tend to look after their game surprisingly well and are putting it to good use. There are 302 proclaimed private game and nature reserves as well as 92 registered hunting farms with a total area of $2225800 \mathrm{ha}$. The income from the sale of live game, carcases, trophies and skins amounted to R5,5 million during 1975 .

\section{SWA is a developing country}

In a sense we are fortunate in that we are still a developing country. We are in a position to learn from the mistakes of others and plan accordingly. I specifically refer to the environment.

We started with the concept of game protection at the turn of the century when the German Colonial Government proclaimed three large game reserves and numerous hunting laws. The accent was placed on protection only. From there we advanced to the idea of game conservation whereby numbers and species were controlled, artificial waters were provided and problem-orientated research was undertaken. The ecosystems as such were ignored. It soon became clear that it was nature in general, and not only the animals, that needed attention. Intensive research programmes were subsequently initiated which were followed up by management plans based on a systems approach. Today we realize that one cannot justify nature conservation areas in isolation and that environmental conservation of the Territory as a whole is the only answer in the long run.

A much neglected aspect was research on tourism itself. Due to the lack of reliable statistics many unfounded statements were made in the past about the benefits and the disadvantages of tourism. Therefore, surveys and studies in depth were undertaken to assess the needs and preferences of local, southern African and overseas visitors, their impact on conservation areas and on the infrastructure of the country and the economy of tourism itself. Our information is more reliable today but 
much is still to be done because the picture constantly changes. Consider the changes brought about by the Jumbo Jet, the four-wheeldrive vehicle, the dune buggy, greater affluence of the masses, more leisure time and better communication media. Problems encountered in the Kruger-, and Yellow Stone National Parks or on The Ciosta Brava, have the habit of surfacing in our country after a number of years albeit on a smaller scale. Seeing that a number of undeveloped conservation areas still exist in SWA and because these areas are of the few natural renewable resources of the Territory, it is imperative for us to look before we leap when it comes to the exploitation of these assets.

In a sense, SWA is fortunate not to have big industries to speak of. Therefore, we may enjoy the luxury of clean air and water. The country side is largely unspoilt but micro-wave towers and power lines are beginning to mar the sky-line, dams canals and pipe-lines are being planned, open-pit mines are being opened up in the Namib Desert and pressure is felt on our conservation areas. With our expanding population and everything that goes with it this pressure will increase.

\section{Conclusion}

South West Africa is fortunate in having a large variety of conservation areas to suit the different needs, tastes and pockets of its own peoples as well as those of visitors. The income derived from tourism is considerable and has been on the increase for 20 years, This year it dropped 6,5\% for the first time. The tourist industry employs more than 5000 people directly. Many more are employed in associated concerns. It is important that their livelihood should be stable.

Whether the future will remain rosy is debatable. Outside influences such as rising costs and inflation coupled with our problems of long distances, our expensive infrastructure and possible changes in state spending priorities are sobering thoughts. In addition much of our tourism revenue leaves the country again to pay for the goods imported to provide for the needs of the tourist. Coupled with this there is the threat to the future of conservation areas and the question whether they can really withstand the pressures building up against them. Huge schemes evisaged by engineers are at present one of our biggest headaches. Fortunately ecological impact studies on a multi-disciplinary basis are under way because we believe that most of these schemes cost more and are of smaller benefit than was originally stated. The long-term undesirable side-effects are seldom pointed out and valuable natural renewable resources are lost in the end.

I believe that the answer lies in the fact that no government can afford to subsidize conservation areas in the long run. Neither can these areas be looked upon as luxuries for the rich, aesthetic necessities, open-air laboratories for the sake of science alone or sacred trusts to be handed unspoilt to our children. Conservation should also be economically 
defensible and it should meet the needs of all the sections of the local population, rich and poor, and enjoy their full support. If this is not the case, the alternative is too awful to contemplate.

\section{REFERENCES}

GIESS, W 1971. A preliminary vegetation map of South West Africa. Dinteria 4:5-114. SOUTH WEST AFRICA SURVEY. 1974. Published by the Department of Foreign Affairs of the Republic of South Africa. 